\title{
The manifestation of VIS-NIRS spectroscopy data to predict and map soil texture in the Triffa plain (Morocco)
}

\author{
Ayoub Lazaar ${ }^{1, *}$, Biswajeet Pradhan², Zakariae Naiji1 ${ }^{1}$,Abdelali Gourfi, Kamal El Hammouti, \\ Karim Andich ${ }^{4}$, Abdelilah Monir ${ }^{5}$ \\ ${ }^{1}$ Dept. of Geology, Faculty of Sciences, Mohammed First University, Oujda, Morocco \\ ${ }^{2}$ Center for Advanced Modelling and Geospatial Information Systems, Faculty of Engineering and Information Technology, \\ Sydney, Australia \\ ${ }^{3}$ Dept. of Geology, Faculty of Sciences and Techniques, Cadi Ayyad University, B.P. 549, Marrakech \\ ${ }^{4}$ Dept. Geomatics and Soil Science, National Institute of Agronomic Research, Oujda, Morocco \\ ${ }^{5}$ Dept. of Mathematics, EDP and Scientific Computing Team, Faculty of Sciences, Moulay Ismail University, Meknes, Morocco \\ *Corresponding author: lazaar.ayoub1@gmail.com
}

\begin{abstract}
The use of standard laboratory methods to estimate the soil texture is complicated, expensive, and time-consuming and needs considerable effort. The reflectance spectroscopy represents an alternative method for predicting a large range of soil physical properties and provides an inexpensive, rapid, and reproducible analytical method. This study aimed to assess the feasibility of Visible (VIS: 350-700 nm) and Near-Infrared and Short-Wave-Infrared (NIRS: 701-2500 $\mathrm{nm}$ ) spectroscopy for predicting and mapping the clay, silt, and sand fractions of the soils of Triffa plain (north-east of Morocco). A total of 100 soil samples were collected from the non-root zone of soil $(0-20 \mathrm{~cm})$ and then analyzed for texture using the VIS-NIRS spectroscopy and the traditional laboratory method. The partial least squares regression (PLSR) technique was used to assess the ability of spectral data to predict soil texture. The results of prediction models showed excellent performance for the VIS-NIRS spectroscopy to predict the sand fraction with a coefficient of determination $\mathrm{R}^{2}=0.93$ and Root Mean Squares Error $(\mathrm{RMSE})=3.72$, good prediction for the silt fraction $\left(\mathrm{R}^{2}=0.87\right.$; RMSE $=4.55)$, and acceptable prediction for the clay fraction $\left(\mathrm{R}^{2}=0.53\right.$; RMSE $\left.=3.72\right)$. Moreover, the range situated between 2150 and $2450 \mathrm{~nm}$ is the most significant for predicting the sand and silt fractions, while the spectral range between 2200 and $2440 \mathrm{~nm}$ is the optimal to predict the clay fraction. However, the maps of predicted and measured soil texture showed an excellent spatial similarity for the sand fraction, a certain difference in the variability of clay fraction, while the maps of silt fraction show a lower difference.
\end{abstract}

Keywords: Partial least squares regression; reflectance spectra; spectroscopy; soil texture; texture mapping.

\section{Introduction}

Soil texture classification and mapping are an essential key for agriculture lands monitoring and management. The soil texture corresponds to the relative abundance of the size fractions by weight: sand, silt, and clay (Lucadamo $\&$ Leone, 2015). It is a good indicator for controlling the spatial and temporal evolution of soils in order to preserve and manage them sustainably. Soil texture gives excellent information about the soil capacity in water retention (Emerson, 1995), the soil erodibility factor (Gourfi et al., 2018), the soil biological activity, and organic matter storage (Hassink et al., 1993), and it is one of the essential parameters in the spatial characterization of aquifers and soil moisture variation (Mohammad et al., 2016; Al Jassar \& Rao, 2015). It is one of the most important characteristics used in the soil classification system and taxonomy (Hristov, 2013).

The mapping of soil texture in different scales of Morocco, in order to benefit with better variability of soil texture, required collecting and analyzing a large number of soil samples in the laboratory. Also, the use 
of standard laboratory methods to estimate texture such as hydrometer-pipette and sedimentation methods (Jacob \& Topp, 2002; Smith \& Mullins, 1991) is complicated, costly, and time-consuming and needs considerable effort (Lazaar et al., 2019). For this reason, in recent years, the researchers have given a particular interest to the VIS-NIR spectroscopy. It is an inexpensive, rapid, and reproducible analytical method (Timezel, 2015; Gholizadeh et al., 2017). The advantage of this method lies in the sample preparation, which requires only a few minutes for each sample compared to the traditional laboratory method, and it is a useful tool for large-scale digital soil mapping, in which the number of soil samples is enormous, while the cost of soil analysis is expensive (Lazaar et al., 2019). Currently, the VIS-NIRS spectroscopy represents an alternative method for predicting a large range of soil physical properties such as the texture, structure, and bulk density (Emerson, 1995; Gomez et al., 2008; Leone et al., 2012; Curcio et al., 2013; Virgawati et al., 2018). Concerning the use of VIS-NIRS spectroscopy to predict soil texture, Rossel \& Webster (2012) and Lacerda et al. (2016) found that the prediction is robust for the sand and clay fractions but is not reliable for the silt fraction. However, Sørensen \& Dalsgaard (2005) indicated that the accuracy of NIR equations for determination of clay was related to the calibrated concentration range, the spectral regions used for calibration, and the spectral pretreatment procedure.

Many techniques are used to discern the response of soil attributes using spectral data such as the principal component analysis (PCR) (Pirie et al., 2005), the continuum removal (Curcio et al., 2013), the support vector machine regression (SVMR) (Wang et al., 2014), and the partial least squares regression (PLSR) (Gomez et al., 2008; Leone et al., 2012; Gholizadeh et al., 2016), but several studies showed that the most common calibration method used for soil spectra in order to predict the soil texture with a better model is the PLSR method (Viscarra Rossel et al., 2006; Curcio et al., 2013), although the preprocessing and transformation of spectral data generate models with different quality of prediction (Hobley \& Prater, 2018).

The main objective of this study, compared with other studies carried out by Curcio et al. (2013) and Virgawati et al. (2018), in order to predict the soil texture, is to assess the feasibility of the data of the VIS-NIRS spectroscopy to predict and map the soil texture (clay, silt, and sand) in the semi-arid region of Triffa plain, using the PLSR method, and to show the influence of the texture of the soil samples used to make the prediction on the coefficient of determination.

\section{Materials and methods}

\subsection{Study area and soil samplings}

The study area is located in Triffa plain in the northeast of Morocco along the Algerian border (longitude $34^{\circ} 56^{\prime} 32.67^{\prime \prime} \mathrm{N}$; latitude 2॰24’05.95” W) (Figure 1). Triffa plain is characterized by a semi-arid climate, with precipitations from 200 to $300 \mathrm{~mm} /$ year (Boughriba et al., 2006) and a regime dominated by strong irregularity in space and time (Fekkoul, 2012). The study area represents the most fertile and productive agricultural zone in the oriental region. It is characterized by six types of soils represented by the isohumic, fersialitic, brown calcareous, hydromorphic, less-developed, and rendzina soils (Lazaar et al., 2019). Regarding the soil texture of this study area, Lazaar et al. (2020) indicated that all soil types of the Triffa plain are characterized by silt-loam and sandy-loam texture. Soil sampling was carried out in August 2018 with the density of one sample per $1.5 \mathrm{~km} 2$. A total of 100 soil samples were collected in the non-root zone $(0-20 \mathrm{~cm})$ of soil with a mechanical auger, georeferenced using a Global Positioning System (GPS), and then transported to the laboratory in order to analyze their texture by using the densimeter method (Estefan et al., 2013). The principle of this method is as follows: all particles larger than $2 \mathrm{~mm}$ in diameter are removed by a $2 \mathrm{~mm}$ sieve. The sieved sample is homogenized, and a weight of approximately $40 \mathrm{~g}$ (dry weight) is mixed with a volume of water containing a dispersing agent $\left(\left(\mathrm{NaPO}_{3}\right)_{6}, \mathrm{HCl}, \mathrm{H}_{2} \mathrm{O}_{2} \ldots\right)$ and introduced into a cylinder. Subsequently, the density of the mixture is measured with a hydrometer at various time intervals. The density obtained as a function of the sedimentation time gives the particle size of the analyzed sample. A blank line has to be placed above, but not below them. 


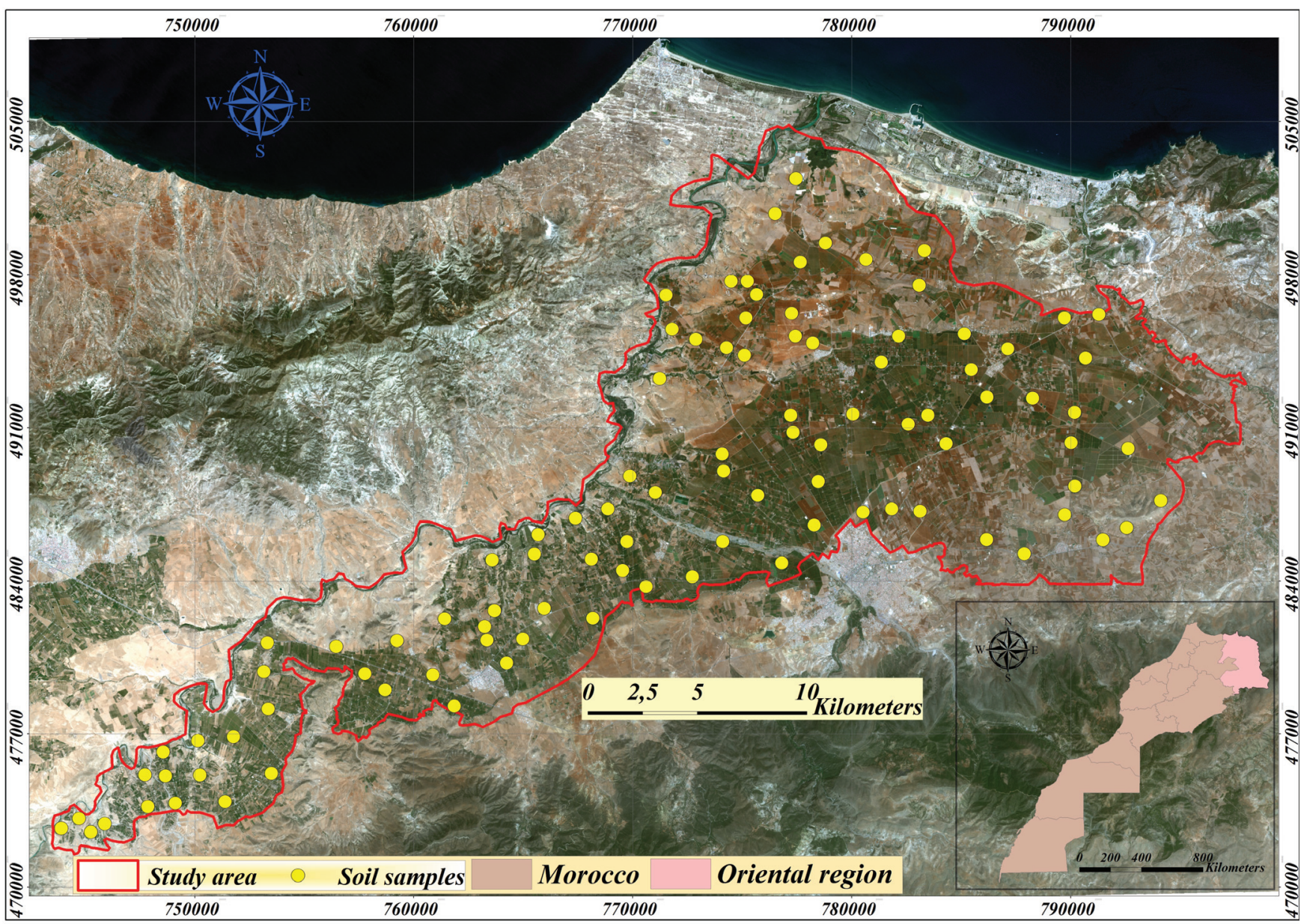

Fig. 1. Location of the study area of Triffa plain and the soil sample.

\subsection{Spectral measurement and data pretreatments}

The soil samples collected in the study area were airdried to $100{ }^{\circ} \mathrm{C}$ for 24 hours, in order to remove any effect of moisture before measuring soil reflectance and then placed in Petri dishes with a diameter of $95 \mathrm{~mm}$ and a thickness of $15 \mathrm{~mm}$. The spectral measurements were conducted using an ASD FieldSpec III portable spectroradiometer with a wavelength of 350-2500 nm. The wavelength configuration of the spectroradiometer is organized as the VIS spectral domain (350-700 nm), the NIR domain (700-1300 nm), and the SWIR1 (1300-1800 $\mathrm{nm})$ and SWIR2 (1800-2500 nm) domains. The spectral measurements were conducted using two steps; the first step consists of measuring the reflectance on a white reference (spectralon) in order to calibrate the sensor of measurement and in the second step, the soil reflectance was measured with an optical probe integrated into a pistol grip with an illuminator Halogen lamp (Figure 2). These measurements were repeated 25 times for each soil sample in order to benefit from a good reflectance of soil, and the measurement sensor was recalibrated with the white reference every ten successive measurements. In order to obtain a better prediction of soil texture, the spectral data had to go through several pretreatments to remove the signal noise and to correct for nonlinearities of spectral data (Stenberg et al., 2010; Tian et al., 2013). The first step of preprocessing applied for the spectral data used in this study was to remove the spectral domain 350 $399 \mathrm{~nm}$ and 2451-2500 $\mathrm{nm}$ because it was affected by the noise. The spectral bands between 400 and $2450 \mathrm{~nm}$ were transformed into the first derivative and then smoothed with the Savitzky-Golay algorithm with a window size of 11 and a polynomial of order 2 (Savitzky \& Golay, 1964; Ren et al., 2009), for eliminating the artificial noise caused by the spectroradiometer device (Gholizadeh et al., 2016). The pretreatment was performed using the Unscrambler software. 


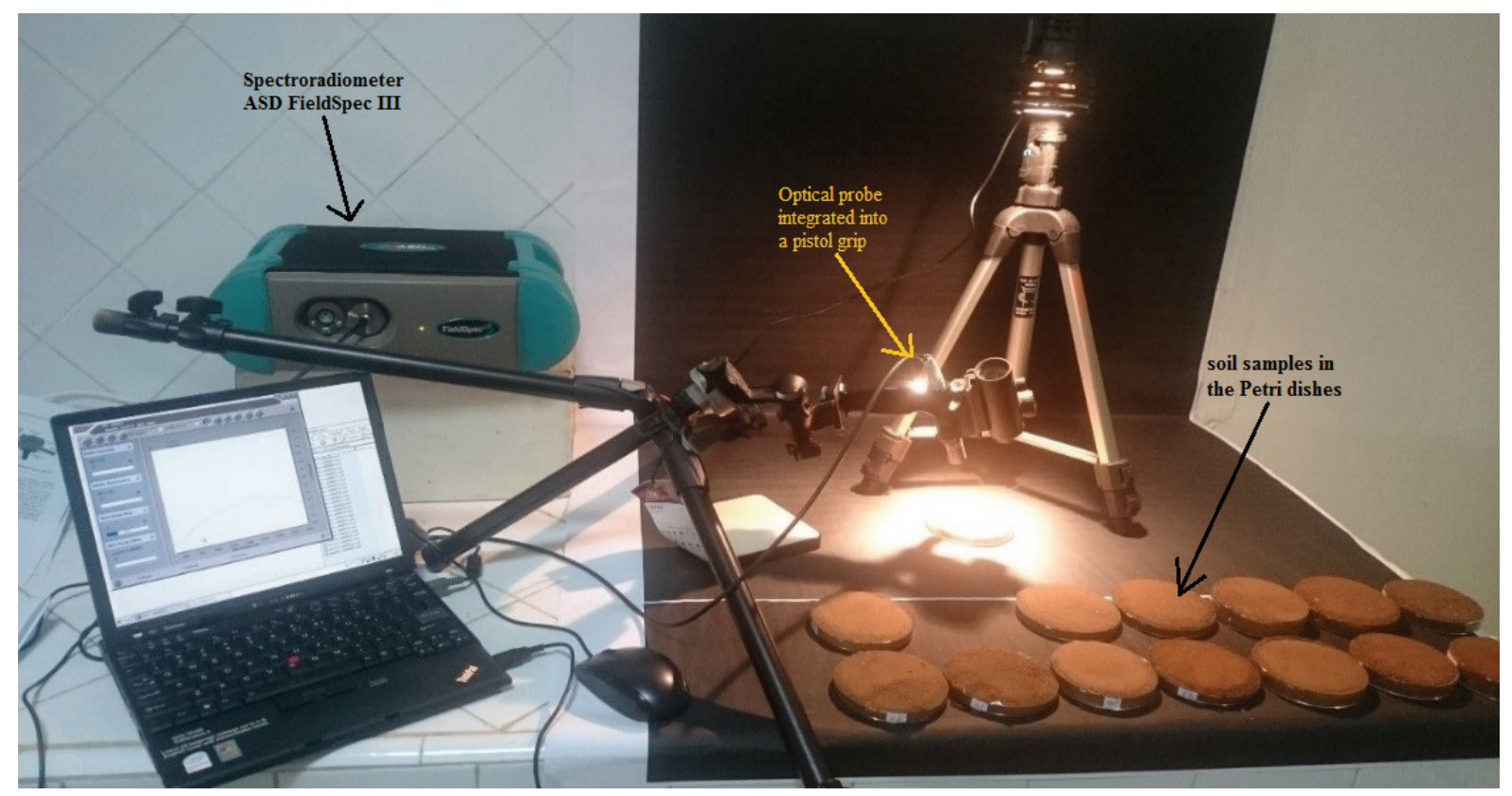

Fig. 2. Experimental configuration used to measure the reflectance of soil samples.

\subsection{Partial least squares regression (PLSR) and soil} texture mapping

The main objective of the statistical analysis was to determine the performance of the data of VIS-NIRS spectroscopy to predict the soil texture and to identify the range of spectral bands used in the prediction models. The dataset used in this study was divided into two groups, $75 \%$ for calibration and $25 \%$ for validation. The PLSR is a method for relating two data matrices $\mathrm{X}$ and $\mathrm{Y}$ through a linear multivariate model and is widely used in reflectance spectroscopy data analyses (Volkan Bilgili et al., 2010). In this study, the PLSR was used to relate the reflectance spectra of the calibration dataset with measured soil texture. The models' prediction quality was evaluated by the coefficient of determination $\left(\mathrm{R}^{2}\right)$ and the RMSE.

The spatial distribution maps of the soil texture were constructed using the measured values obtained from the conventional method of laboratory, and the predicted values from calibrated models of sand, silt, and clay. The kriging method (Zhang et al., 2013) of ArcGIS software was employed to make the maps variability of soil texture in the study area of Triffa plain.

\section{Results and discussion}

\subsection{Soil textural properties}

Descriptive statistical results of soil texture for all samples analyzed $(\mathrm{N}=100)$ are summarized in Table 1 . The studied samples are characterized by sand fraction ranging from $16.5 \%$ to $74.75 \%$ with an average value of $39 \%$, silt fraction varied between $20.25 \%$ and $83.50 \%$ with an average of $54.95 \%$, and clay fraction varied between $0 \%$ and $16 \%$ with an average of $5 \%$. This result indicates that the sand and silt fractions have a strong distribution and dominance in the soils of Triffa plain in relation to the clay fraction. Moreover, the texture classification according to the USDA triangle shows that the soils of the study area are characterized by the silt-loam (Figure 3), sandy-loam, and loam textures; our results confirmed those obtained by Lazaar et al. (2019).

Table 1. Descriptive statistics for the soil texture of the samples analysed.

\begin{tabular}{cccccc}
\hline Fraction & Minimum & Maximum & Mean & Median & $\begin{array}{c}\text { Standard } \\
\text { Deviation }\end{array}$ \\
\hline Clay (\%) & 0 & 16.0 & 5.6 & 5.0 & 3.8 \\
\hline Silt (\%) & 20.2 & 83.5 & 52.9 & 54,9 & 12.3 \\
\hline Sand (\%) & 16.5 & 74.7 & 41.3 & 39.0 & 12.6 \\
\hline
\end{tabular}




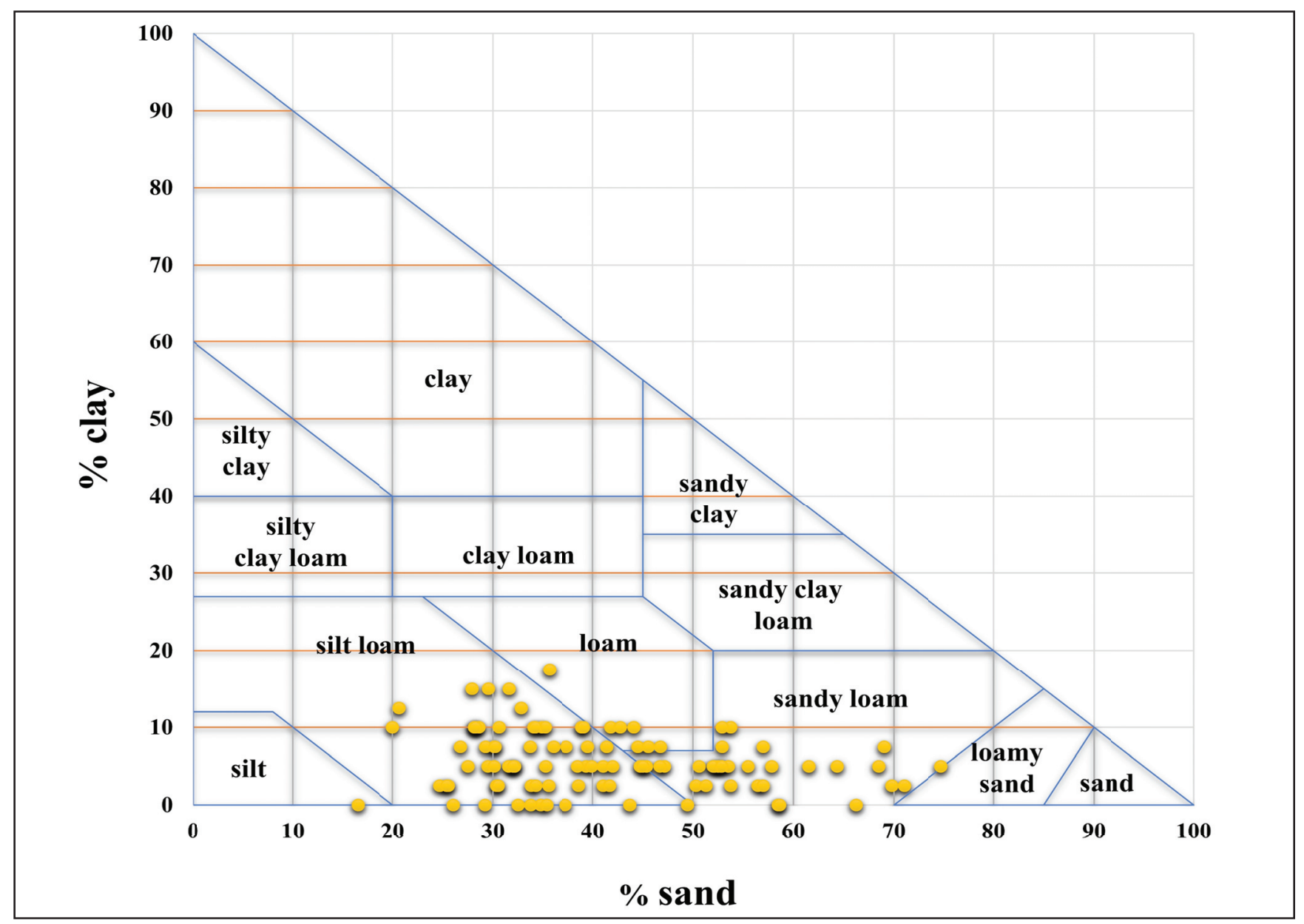

Fig. 3. Texture classification of soil samples according to the USDA texture triangle.

\subsection{VIS-NIRS spectra of soil data and spectra processing}

The spectra of soil samples measured in laboratory with the ASD FieldSpec spectroradiometer are plotted in Figure 4a. In general, the VIS-NIRS spectra of soil samples have a similar reflectance shape, in which the reflectance is lower in the VIS range (400-700 nm) and higher in the NIRS range (701-2450 nm) with the presence of several absorption bands of different intensities around $1400 \mathrm{~nm}, 1900 \mathrm{~nm}$, and $2200 \mathrm{~nm}$. According to Bishop et al. (2008), the strong absorption bands detected around 1400 and $1900 \mathrm{~nm}$ are due to the vibrational frequency of $-\mathrm{OH}$ group in water and the molecular water contained in minerals, while the band observed near $2200 \mathrm{~nm}$ is related to the clay or hydroxyl mineral (Bishop et al., 1994) and the characteristics of organic matter (Vašát et al., 2015). Also, the VIS range is marked by many absorption peaks with lower intensity near 430, 530, and $650 \mathrm{~nm}$, which are attributed to the presence of iron oxide and a small amount of haematite (Fe2O3) (Sherman \& Waite, 2000; Rossel \& Behrens, 2010). Concerning the spectra processing in order to enhance the robustness of prediction models of the soil texture and to detect the important spectral bands used in the prediction, many processing models are tested, but in the present study, the transformation of spectral data (400-2500 nm) with the first derivative algorithm and the smoothing with the Savitzky-Golay algorithm with a window size of 11 and a polynomial of order 2 (Figure 4b) were the better preprocessing models. 


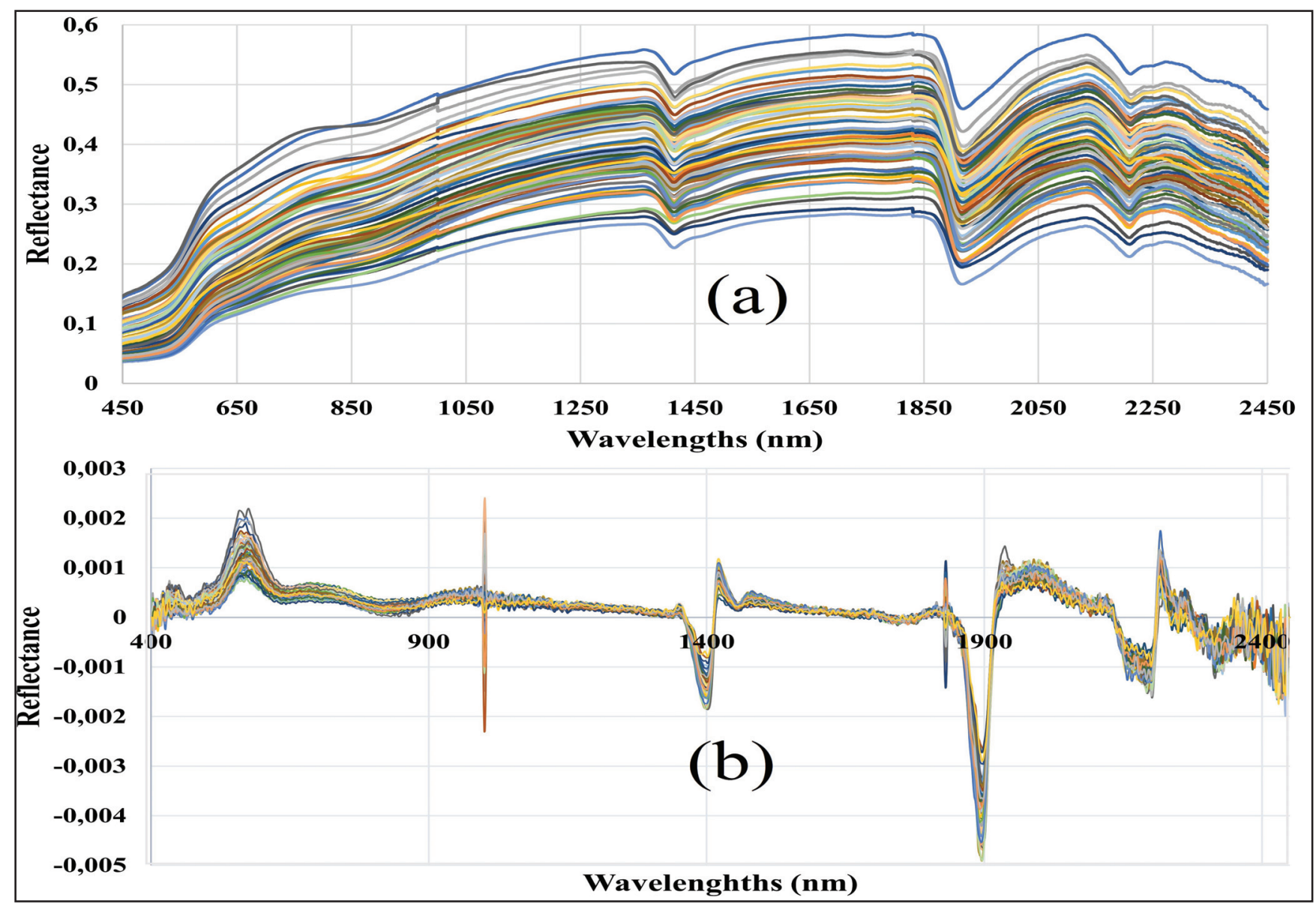

Fig. 4. Representative VIS-NIRS spectra of soil samples (a) and the smoothed and $1^{\text {st }}$ derivative preprocessed soil spectra (b).

\subsection{Predictive models of soil texture}

The summary of prediction models for the soil texture (sand, silt, and clay fractions) of the calibration and validation dataset is shown in Table 2, as well as the scatter plots of the measured against predicted concentrations (Figure 5). Results of the $\mathrm{R}^{2}$ and the RMSE of the PLSR models for the calibration dataset (Table 2 and Figure 5a) indicated that the prediction is better for the sand fraction with $\mathrm{R}^{2}=0.94$ and $\mathrm{RMSE}=3.18$, good for the silt fraction with $\mathrm{R}^{2}=0.87$ and $\mathrm{RMSE}=3.38$, and acceptable for the clay fraction with $\mathrm{R}^{2}=0.56$ and $\mathrm{RMSE}=2.35$. The quality of the calibration models was tested by the validation dataset. Results of the validation models (Table 2 and Figure 5b) have confirmed those obtained by the calibration models, in which the quality of prediction for the sand is better $\left(\mathrm{R}^{2}=0.92\right.$ and $\left.\mathrm{RMSE}=3.72\right)$, good for the silt $\left(\mathrm{R}^{2}=0.87\right.$ and $\mathrm{RMSE}=4.55)$, and acceptable for the clay $\left(\mathrm{R}^{2}=0.53\right.$ and RMSE $=2.0$ ). Moreover, these results indicate that the PLSR method had a higher accuracy to relate the reflectance spectra with the sand and silt fractions, while the other one had an acceptable efficiency for the clay fraction. These results obtained in our study have confirmed the $\mathrm{R}^{2}$ values introduced in the literature by many authors (Curcio et al., 2013; Gholizadeh et al., 2016; Hobley \& Prater, 2018). These results conclude two things: the first is that the accuracy to predict the different fractions of soil texture (sand, silt, and clay) using the PLSR method is related to the percentages of the three fractions; for example, in our study, the percentage of sand and silt is high compared to the low percentage of the clay fraction in all soil samples; this provides better prediction models for the sand and silt fractions and an acceptable prediction of clay. The second is that the quality of prediction models of the sand and silt fractions depended on, and is influenced directly by, the percentage of clay fraction. This conclusion confirmed the result obtained by Curcio et al. (2013). 
Table 2. Summary of the PLSR prediction models of soil texture (sand, silt, and clay) for the calibration and validation dataset.

\begin{tabular}{ccccc}
\hline & \multicolumn{2}{c}{ Calibration } & \multicolumn{2}{c}{ Validation } \\
\hline & $\mathrm{R}^{2}$ & RMSE & $\mathrm{R}^{2}$ & RMSE \\
\hline Clay & 0.56 & 2.35 & 0.53 & 2.0 \\
\hline Silt & 0.87 & 4.38 & 0.87 & 4.55 \\
\hline Sand & 0.94 & 3.18 & 0.92 & 3.72 \\
\hline
\end{tabular}
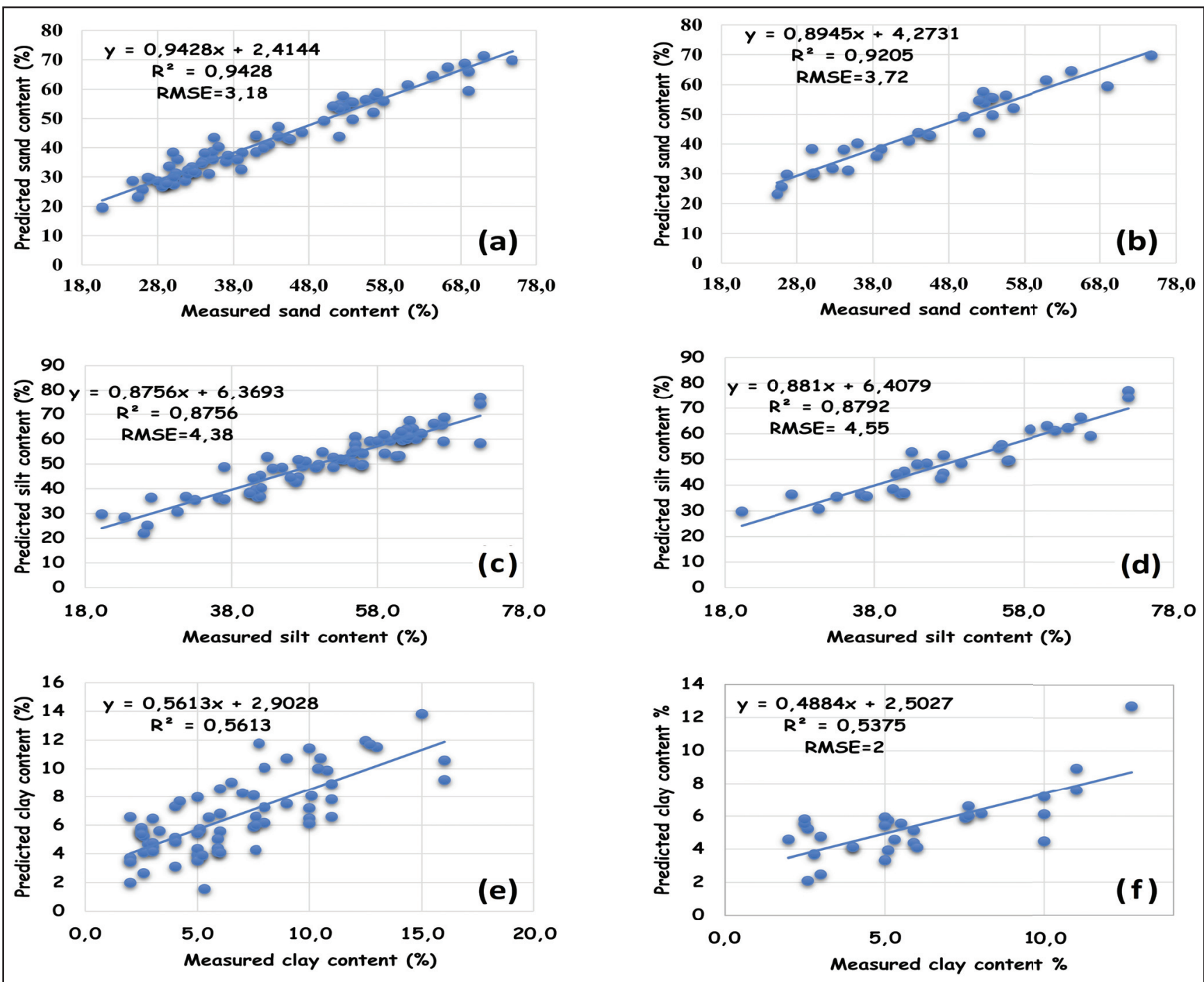

Fig. 5. Scatter plots of measured versus predicted soil texture obtained by PLSR method for the calibration ((a): sand; (b): silt; and (e): clay) and validation ((b): sand; (d): silt; and (f): clay) dataset.

3.4. Influential spectral bands used by the PLSR method

The regression coefficient $\left(\mathrm{B}_{0}\right)$, coupled with the wavelengths summarized in Figure 6, was used to identify the critical spectral bands used by the PLSR method to predict soil texture. The results of the regression coefficient showed that the spectral range situated between 2150 and $2450 \mathrm{~nm}$ is the significant range for predicting the sand and silt fractions, while the spectral range situated between 2200 and 2440 is the optimal to predict the clay fraction. Our result confirmed those obtained by Viscarra Rossel et al. (2006). 


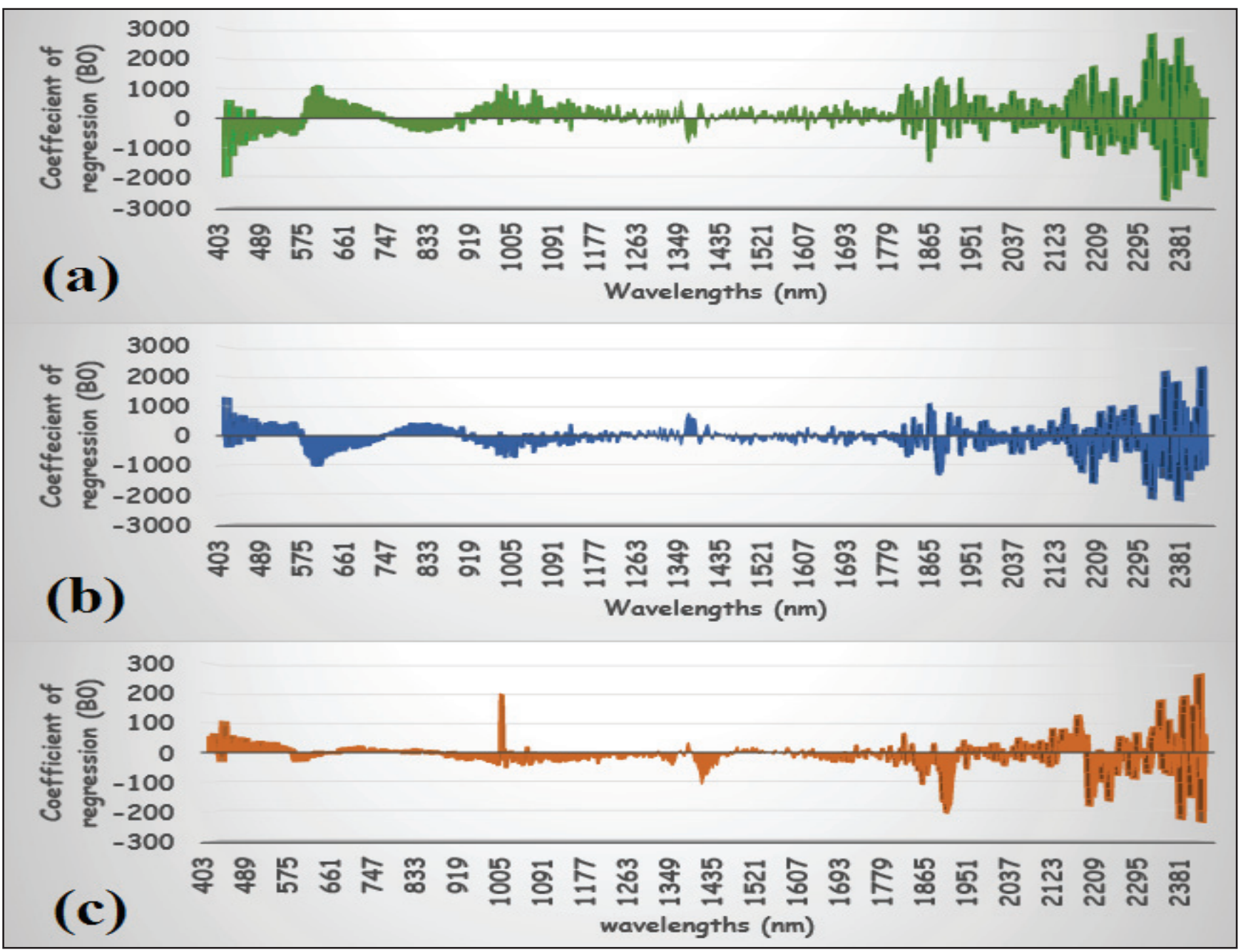

Fig. 6. Variation of regression coefficients with wavelength, obtained from the PLSR analysis for sand (a), silt (b), and clay (c) fractions.

\subsection{Soil texture mapping of soil texture}

The results obtained from the kriging method used to map the measured and predicted soil texture of the three fractions (sand, silt, and clay) are displayed in Figure 7. The comparison between the maps of the measured and predicted clay fraction (Figure 7a) demonstrates a certain difference in the variability of clay fraction and in their values range in the central and south-western part of the study area; this result is confirmed by the acceptable quality obtained by the PLSR method $\left(\mathrm{R}^{2}=0.53\right)$. The maps of silt fraction (Figure $7 \mathrm{~b}$ ) show a lower difference in the variability of silt compared to the clay fraction. This minor difference of silt variability appears in the northeastern and southwestern part of the study area, and this is confirmed by the $\mathrm{R}^{2}=0.87$. 

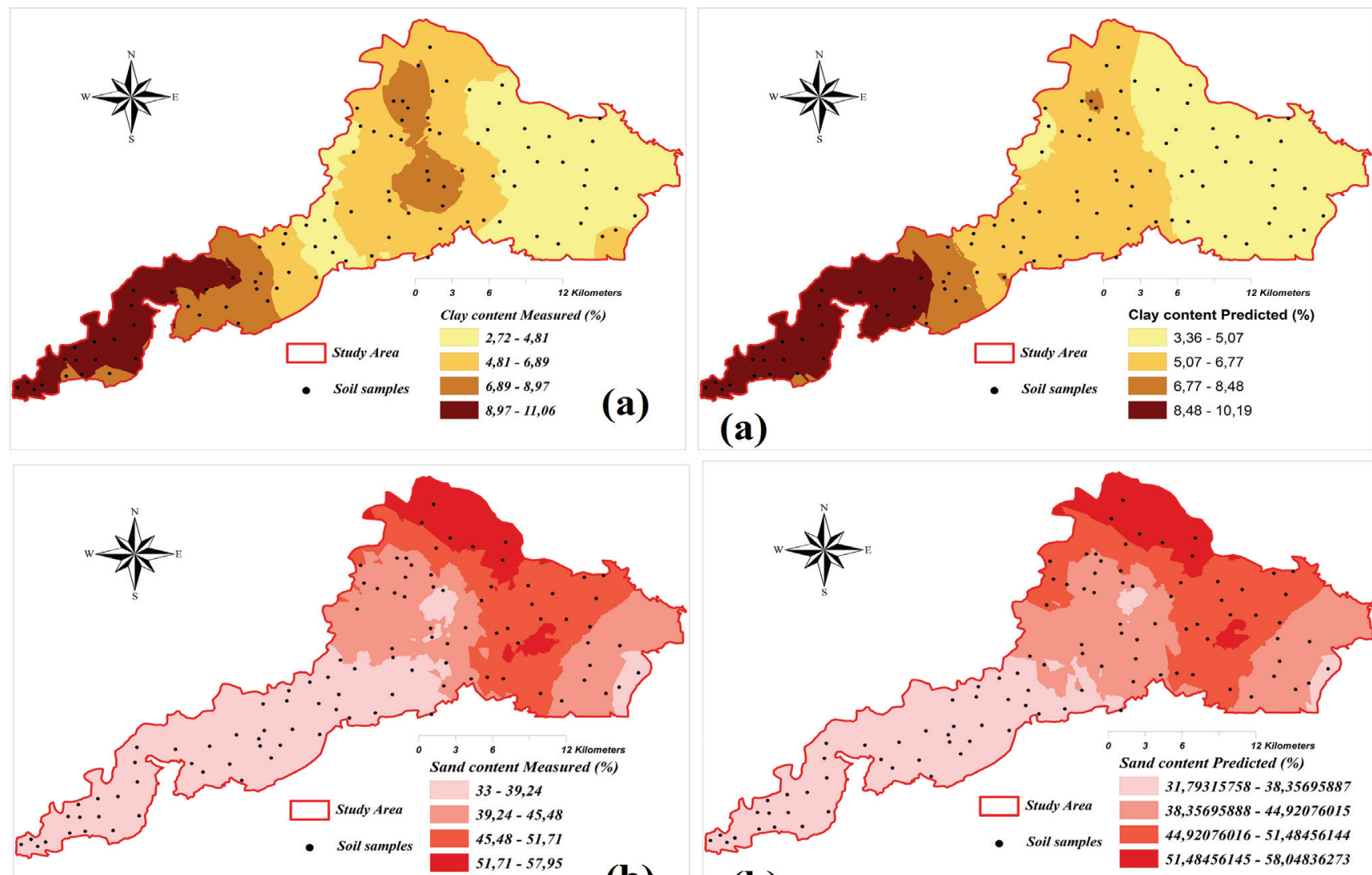

(b)
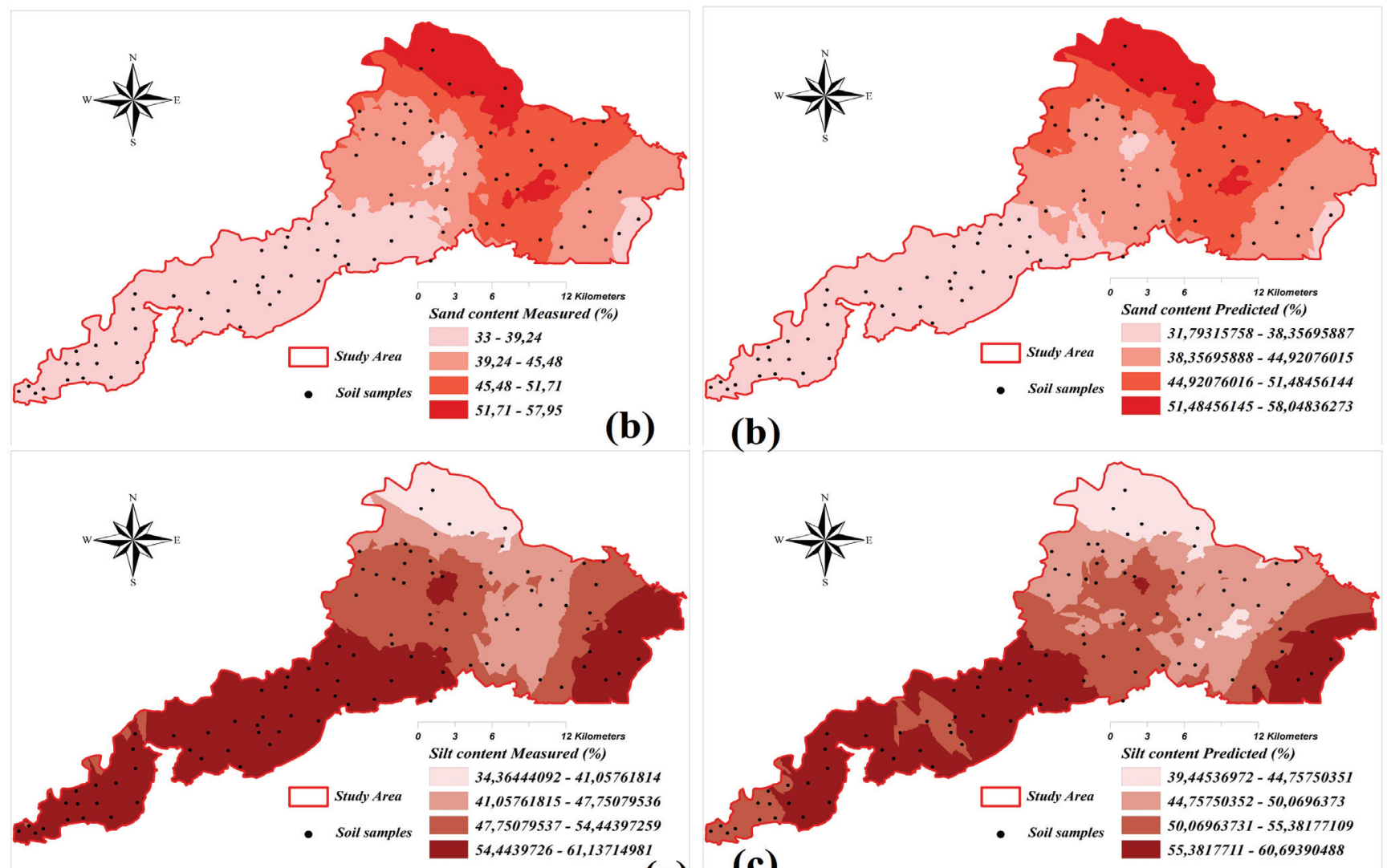

(b)

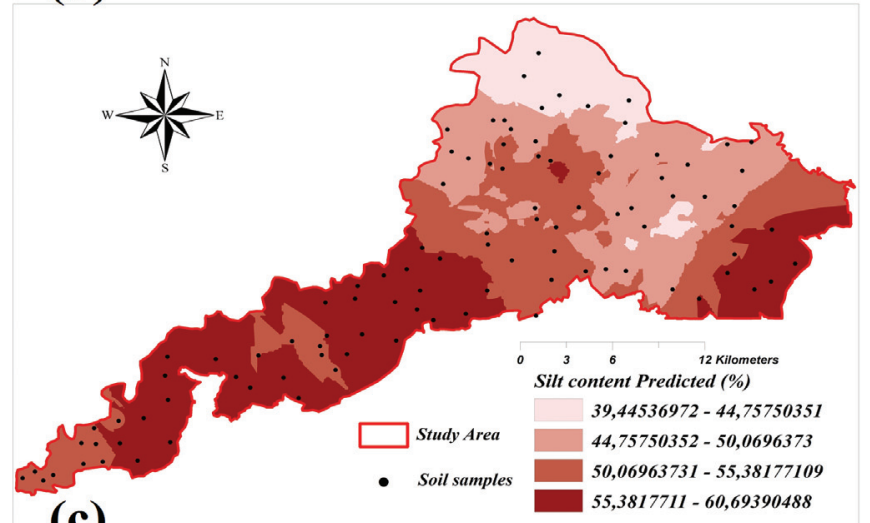

(c)

(c)

Fig. 7. Comparison of laboratory-measured and laboratory VIS-NIRS spectroscopy predicted maps of clay (a), silt (b), and sand (c) fraction.

\section{Conclusion}

The main objective of this paper is to assess the feasibility of VIS-NIRS spectroscopy to estimate and map the soil texture in the semi-arid area of Triffa plain using the PLSR method combined with the data of spectroscopy. The main conclusions that can be drawn from this study are as follows:

- The VIS-NIRS spectroscopy is an efficient and feasible method for predicting the soil texture, which is excellent for the sand, good for the silt, and acceptable for the clay fractions. This difference in prediction accuracy is related to the texture of soil samples of Triffa plain dominated by the sand and silt fractions and poor for the clay fraction. Moreover, the prediction accuracy of sand and silt is dependent and influenced by the percentage of the clay fraction.

- The spectral range situated between 2150 and $2450 \mathrm{~nm}$ is significant for predicting the sand and silt fractions, while the range from 2200 to $2440 \mathrm{~nm}$ is optimal to predict the clay fraction. 


\section{References}

Al Jassar, H.K. \& Rao, K.S. (2015). Assessment of soil moisture through field measurements and AMSR-E remote sensing data analysis over Kuwait desert. Kuwait Journal of Science, 42(2): 250-260.

Al Maliki, A., Owens G., Hussain, M.H., Al-Dahaan, S. \& Al-Ansari, N. (2018). Chemometric Methods to Predict of $\mathrm{Pb}$ in Urban Soil from Port Pirie, South Australia, using Spectrally Active of Soil Carbon. Communications in Soil Science and Plant Analysis. 49(11): 1370-1383.

Bishop, J.L., Lane, M.D., Dyar, M.D. \& Brown, A.J. (2008). Reflectance and emission spectroscopy study of four groups of phyllosilicates: smectites, kaoliniteserpentines, chlorites and micas. Clay Mineral, 43:35-54.

Bishop, J.L., Pieters, C.M. \& Edwards, J.O. (1994). Infrared spectroscopic analyses on the nature of water in montmorillonite. Clays and Clay Minerals, 42(6): 702716.

Boughriba, M., Melloul, A., Zarhloule, Y. \& Ouardi, A. (2006). Spatial extension of salinization in groundwater and conceptual model of the brackish springs in the Triffa plain (north- eastern Morocco). Comptes Rendus Geoscience, 338(11): 768-774.

Curcio, D., Ciraolob, G., D'Asaroa, F. \& Minacapilli M. (2013). Prediction of Soil Texture Distributions Using VNIR-SWIR Reflectance Spectroscopy. Procedia Environmental Sciences, 19: 494-503.

Emerson, W.W. (1995). Water retention, organic c and soil texture. Australian Journal of Soil Research, 33(2): 241-251.

Estefan, G., Sommer, R. \& Ryan, J. (2013). Methods of Soil, Plant, and Water Analysis: A manual for the West Asia and North Africa region. International Center for Agricultural Research in the Dry Areas (ICARDA). Beirut. Pp.244.

Fekkoul, A. (2012). Groundwater contamination by nitrates, salinity and pesticides: case of the unconfined aquifer of triffa plain (Eastern Morocco). Revue Marocaine des Sciences Agronomiques et Vétérinaires, 2: 12-36.

Gholizadeh, A., Saberioon, M.M., Boruvka, L. \& Vasat, R. (2016). A memory-based learning approach as compared to other data mining algorithms for the prediction of soil texture using diffuse reflectance spectra. Remote Sensing, 8(4): 1-17.

Gholizadeh, A., Carmon, N., Klement, A., Ben-Dor, E.
\& Borùvka, L. (2017). Agricultural soil spectral response and properties assessment: Effects of measurement protocol and data mining technique. Remote Sensing, 9(10): 1-14.

Gomez, C., Lagacherie, P. \& Coulouma, G. (2008). Continuum removal versus PLSR method for clay and calcium carbonate content estimation from laboratory and airborne hyperspectral measurements. Geoderma, 148(2): 141-148.

Gourfi, A., Daoudi, L. \& Shi, Z. (2018). The assessment of soil erosion risk, sediment yield and their controlling factors on a large scale: Example of Morocco, Journal of African Earth Sciences. 147: 281-299.

Hassink, J., Bouwman, L.A., Zwart, K., B., Bloem, J. \& Brussard, L., (1993). Relationships between soil texture, physical protection of organic matter, soil biota, and $\mathrm{c}$ and $\mathrm{n}$ mineralization in grassland soils. Geoderma, 57(1-2): 105-128.

Hobley, E.U. \& Prater, I. (2018). Estimating soil texture from vis-NIR spectra. European Journal of Soil Science, 70(1): 83-95.

Hristov, B. (2013). Importance of soil texture in Soil Classification systems. Balkan Ecology, 16(2): 137-139.

Jacob H.D. \& Topp, G.C. (2002). Methods of Soil Analysis: Part 4 Physical Methods. SSSA, Wisconsin. Pp. 294.

Lacerda, M.P.C., Demattê,J.A.M., Sato, M.V., Fongaro, C.T. et al. (2016). Tropical texture determination by Proximal Sensing using a regional spectral library and its relationship with soil classification. Remote Sensing, 8(9): 1-20.

Lazaar, A., Mahyou, H., Gholizadeh, A., EI Hammouti, K., Bilal, M., Andich, K. et al. (2019). Potential of VIS NIR spectroscopy to characterize and discriminate topsoils of different soil types in the Triffa plain (Morocco). Soil Science Annual, 70(1): 54-63.

Lazaar, A., Mouazen, A.M., El Hammouti, K., Fullen, M., Pradhan, B., Memon, M.S. et al. (2020). The application of proximal visible and near-infrared spectroscopy to estimate soil organic matter on the Triffa Plain of Morocco. International Soil and Water Conservation Research, 8(2): 195-204.

Leone, A., Viscarra-Rossel, R.A., Amenta, P. \& Buondonno, A. (2012). Prediction of Soil Properties with PLSR and vis-NIR Spectroscopy: Application 
to Mediterranean Soils from Southern Italy. Current Analytical Chemistry, 8: 283-299.

Lucadamo, A. \& Leone, A. (2015). Principal component multinomial regression and spectrometry to predict soil texture. Journal of Chemometrics, 29(9): 514-520.

Mohammad, A.H., Shatanawi, K. \& Odeh, T. (2016). A modified modeling of potentiality and vulnerability of the groundwater resources in Amman Zarqa Basin, Jordan. Kuwait Journal of Science, 43(1): 208-221.

Pirie, A., Singh, B. \& Islam, K. (2005). Spectroscopic Techniques to Predict Several Soil Properties. Australian Journal of Soil Research, 43: 713-721.

Ren, H.Y., Zhuang, D.F., Singh, A.N., Pan, J.J., Qid, D.S. et al. (2009). Estimation of As and $\mathrm{Cu}$ Contamination in Agricultural Soils Around a Mining Area by Reflectance Spectroscopy: A Case Study. Pedosphere. 19(6): 719726.

Rossel, R.A.V. \& Behrens, T. (2010). Using data mining to model and interpret soil diffuse reflectance spectra. Geoderma. Elsevier B.V., 158(1-2): 46-54.

Savitzky, A. \& Golay, M.J.E. (1964). Smoothing and Differentiation of Data by Simplified Least Squares Procedures. Analytical Chemistry, 36(8): 1627-1639.

Sherman, D.M. \& Waite, T.D. (2000). Electronic spectra of $\mathrm{Fe} 3+$ oxides and oxide hydroxides in the near IR to near UV. American Mineralogist, 70: 1262-1269.

Smith, K.A. \& Mullins, C.E. (1991). Soil and Environmental-Analysis: Physical methods. Dekker, New York. Pp. 651.

Sørensen L.K. \& Dalsgaard, S. (2005). Determination of Clay and Other Soil Properties by Near Infrared Spectroscopy. Soil Science Society of America Journal, 69:159.

Stenberg, B. et al. (2010). Visible and Near Infrared Spectroscopy in Soil Science. Advances in Agronomy, 107: 163-215.

Tian, Y., Zhang, J., Yao, X., Cao, W. \& Zhu, Y. (2013). Laboratory assessment of three quantitative methods for estimating the organic matter content of soils in China based on visible/near-infrared reflectance spectra. Geoderma, 202-203: 161-170.

Temizel, K.E. (2015). Estimation of the phenolics content of St. John's wort (Hypericum perforatum L.) grown under different water and salt levels based on reflectance spectroscopy. Kuwait Journal of Science, 42(3): 210-222.
Vašát, R., Kodesova, R., Boruvka, L., Jaksık, O., Klement, A. et al. (2015). Absorption Features in Soil Spectra Assessment. Applied spectroscopy, 69(12): 14251431.

Virgawati, S., Mawardi, M., Sutiarso, L., Shibusawa, S., Segah H. et al. (2018). Mapping the Variability of Soil Texture Based on VIS-NIR Proximal Sensing. Journal of Applied Geospatial Information, 2(1): 108-116.

Viscarra Rossel, R.A., Walvoort, D.J.J., McBratney, A. B., Janik, L.J. \& Skjemstad, J.O. (2006). Visible, near infrared, mid infrared or combined diffuse reflectance spectroscopy for simultaneous assessment of various soil properties. Geoderma, 131(1-2): 59-75.

Volkan Bilgili, A., Van Es, H.M., Akbas, F., Durak, A. \& Hively, W.D. Visible-near (2010). Visible-near infrared reflectance spectroscopy for assessment of soil properties in a semi-arid area of Turkey. Journal of Arid Environments, 74(2): 229-238.

Wang, L., Wang, Q., Zhang, M. \& Wang, X. (2014). Research on parameters of SVRM in time series prediction. Advanced Materials Research, 889-890: 790-794.

Zhang, S.W., Shen C.Y., Chen X.Y., YE H.C., Huang Y.F. et al. (2013). Spatial Interpolation of Soil Texture Using Compositional Kriging and Regression Kriging with Consideration of the Characteristics of Compositional Data and Environment Variables. Journal of Integrative Agriculture, 12(9): 1673-1683.

Submitted : 15/06/2019

Revised : 03/02/2020

Accepted : 18/03/2020

DOI : $10.48129 /$ kjs.v48i1.8012 